\title{
FAKTOR-FAKTOR YANG MEMPENGARUHI AUDIT REPORT LAG PERIODE 2013-2016 DI BURSA EFEK INDONESIA
}

\author{
Yansen Cristian Halim \\ Fakultas Ekonomi, Universitas Tarumanagara Jakarta \\ Email: yansen_cristian@yahoo.com
}

\begin{abstract}
ABSTRAK
Laporan keuangan yaitu informasi yang digunakan oleh suatu perusahaan untuk dapat menyampaikan informasi keuangan suatu perusahaan. Laporan keuangan suatu perusahaan yang sudah go public diwajibkan untuk diaudit. Berdasarkan peraturan Badan Pengawas Pasar Modal (BAPEPAM) Nomor X.K.2. Peraturan tersebut mewajibkan semua perusahaan yang terdaftar di pasar modal untuk dapat menyampaikan laporan keuangan tahunan yang disertai dengan laporan auditor independen. Ketepatan waktu di dalam melakukan menyampaikan laporan keuangan sangatlah penting bagi para pengguna laporan keuangan. Objek penelitian dalam penelitian ini yaitu pengaruh profitabilitas, board size, leverage, ukuran perusahaan dan ownership concentration terhadap audit report lag pada perusahaan manufaktur yang terdaftar di BEI pada periode 2013-2016. Penelitian yang akan dilakukan yaitu penelitian kuantitatif. Populasi di dalam penelitian ini yaitu seluruh perusahaan manufaktur yang terdaftar di Bursa Efek Indonesia (BEI) selama periode 2013-2016 sebanyak 68 perusahaan. Sampel dalam penelitian ini diperoleh menggunakan metode purposive sampling. Data perusahaan manufaktur berupa laporan keuangan yang diperoleh dari situs resmi Bursa Efek Indonesia yaitu www.idx.co.id. Pengujian yang dilakukan dalam penelitian ini yaitu dengan menggunakan analisis statistik deskriptif, uji asumsi klasik dan uji hipotesis. Hasil dari penelitian ini menunjukkan bahwa faktor board size dan leverage berpengaruh signifikan terhadap audit report lag. Sedangkan, faktor profitabilitas, ukuran perusahaan dan ownership concentration menunjukkan tidak memiliki pengaruh yang signifikan terhadap audit report lag.
\end{abstract}

Kata kunci: profitabilitas, $B S$, leverage, SIZE, OC, $A R L$

Kontributor: Herman Ruslim

\section{PENDAHULUAN}

Laporan keuangan yaitu informasi yang dapat digunakan oleh perusahaan dalam menyampaikan informasi keuangan di suatu perusahaan. Laporan keuangan digunakan oleh seorang investor untuk menilai prospek perusahaan dan juga digunakan oleh seorang kreditor sebagai acuan untuk menilai kemampuan keuangan suatu perusahaan dalam melunasi pinjaman sebelum memutuskan untuk memberikan pinjaman kepada suatu perusahaan. Laporan keuangan perusahaan yang sudah go public diwajibkan untuk diaudit karena setiap perusahaan yang telah go public diwajibkan untuk menyampaikan laporan keuangan yang disusun sesuai dengan standar akuntansi keuangan dan telah diaudit oleh auditor independen sesuai dengan peraturan BAPEPAM.

Berdasarkan peraturan Badan Pengawas Pasar Modal (BAPEPAM) Nomor X.K.2 mengenai keputusan dalam penyampaian laporan keuangan secara berkala emiten dan perusahaan publik. Peraturan tersebut mewajibkan kepada semua perusahaan yang terdaftar di dalam pasar modal untuk dapat menyampaikan laporan keuangan tahunan yang disertai laporan auditor independen paling lambat pada akhir bulan ketiga setelah tanggal laporan keuangan tahunan. Bagi perusahaan yang terlambat melakukan menyampaikan laporan keuangan tahunan sesuai dengan peraturan BAPEPAM Nomor X.K.2 akan diberikan sanksi berupa teguran dan denda sesuai peraturan keputusan Direksi PT Bursa Efek Jakarta Nomor: Kep-307/BEJ/07-2004.

Laporan keuangan harus dapat disajikan secara berkala agar menjelaskan setiap perubahan dan informasi terbaru yang terjadi dalam suatu perusahaan yang mungkin dapat mempengaruhi pemakai informasi dalam membuat prediksi dan keputusan. Oleh karena itu, keterlambatan dalam melakukan 
penyampaian informasi dalam laporan keuangan maupun laporan auditor independen kepada publik akan dapat menimbulkan reaksi negatif dari pelaku pasar modal.

Berikut ini yaitu daftar nama perusahaan terbuka (emiten) dalam sektor manufaktur yang mengalami keterlambatan dalam penyampaian laporan keuangan auditan periode 31 Desember 2016:

Tabel 1. Daftar Nama Perusahaan

\begin{tabular}{|c|l|}
\hline No & \multicolumn{1}{|c|}{ Nama Perusahaan } \\
\hline 1. & PT Tiga Pilar Sejahtera Food, Tbk \\
\hline 2. & PT Steel Pipe Industry of Indonesia, Tbk \\
\hline 3. & PT Asia Pasific Investama, Tbk \\
\hline 4. & PT Nipress, Tbk \\
\hline 5. & PT Siantar Top, Tbk \\
\hline 6. & PT Tri Banyan Tirta, Tbk \\
\hline 7. & PT Atmindo, Tbk \\
\hline 8. & PT Arga Pantes, Tbk \\
\hline 9. & PT Century Textile Industry, Tbk \\
\hline 10. & PT Eterindo Wahanatama, Tbk \\
\hline 11. & PT Grand Kartech, Tbk \\
\hline
\end{tabular}

Sumber: www.idx.co.id.

\section{Literatur}

\subsection{Audit report lag}

Pengertian dari audit report lag adalah :

"Audit report lag is the period of completion of the annual financial statement audit measured from the length of days required to obtain independent auditor's report on the company's annual financial report from the date of closing of the company's book which is period December, 31 until the date stamped on the report independent auditor" (Arifuddin et al., 2017).

\subsection{Profitabilitas}

Pengertian dari profitabilitas adalah sebagai berikut:

"Profitability is a financial ratio that is used by an assessment technique in order to evaluate the capability of a company to generate earning. It is reported that the auditing process for profitable companies tends to consume longer time period than companies making losses" (Alkhatib dan Marji, 2012).

\subsection{Board size}

Pengertian dari board size adalah sebagai berikut:

"Board size is an important determinant in order of corporate governance from listed entities globally. Large or small board are more effective in enhancing the quality of manager's responsibilities. Larger boards have collective expertise and more capable for executing their duties. They may equally be capable from having abridged management control" (Ahmed dan Che-Ahmed, 2016). 


\subsection{Leverage}

Pengertian dari leverage adalah sebagai berikut:

"Leverage is refers to gearing. It is where a relationship exists between a firm's liabilities and its assets, that is the total debts used to finance the firm's assets. Leverage is used to measure the firm's ability to repay its financial obligations as they got mature. Firms with greater debts than the equity are regarded as highly leveraged and require longer auditing time and expect high standard auditing services through the hiring of high-quality auditing firms, then incur higher agency and monitoring costs" (Alkhatib dan Marji, 2012).

1.5. Ukuran perusahaan

Pengertian dari ukuran perusahaan adalah sebagai berikut:

"The size of company that is measured by total assets is the most popular factor of audit report lag that has been used in another previous studies. Most of these prior studies found a negative association between the audit delay and the company size. This is possible due to the ability of larger companies to pressure auditors to complete the audit work in timely manner" (Eghlaiow et al., 2012).

\subsection{Ownership concentration}

Pengertian dari ownership concentration adalah sebagai berikut:

"In contrast to the ownership dispersion, the more closely held by companies, where a large percentage from the shares in a company are owned by few major shareholders, are more likely to provide a poor disclosure quality. Majority shareholders can use their power to access internal sources from the information” (Hassan, 2016).

\section{Hubungan antar variabel}

\subsection{Profitabilitas dan audit report lag}

Profitabilitas yaitu kemampuan suatu perusahaan di dalam memanfaatkan aktivanya dalam memperoleh laba. Profitabilitas ini diperlukan di dalam menilai perubahan potensial terhadap sumber daya ekonomi yang mungkin dapat dikendalikan pada masa depan. Menurut Tiono dan Jogic (2013), salah satu penyebab suatu kemunduran dalam melakukan penyampaian laporan keuangan yaitu pelaporan suatu laba atau rugi sebagai indikator good news atupun bad news atas suatu kinerja manajerial. Perusahaan yang sudah mengalami kerugian cenderung menunda waktu pelaporan dengan meminta auditor untuk mengatur waktu audit laporan keuangan yang lebih lama.

$\mathrm{H}_{1} \quad$ : Profitabilitas mempunyai pengaruh yang signifikan terhadap audit report lag.

\subsection{Board size dengan audit report lag}

Ukuran dewan yaitu salah satu komponen dari corporate governance yang dapat mempengaruhi audit report lag suatu perusahaan. Dewan komisaris dan dewan direksi memiliki banyak fungsi pengawasan atas kebijakan pengurusannya, jalannya pengurusan pada umumnya, baik mengenai perseroan maupun usaha perseroan, dan dapat memberi nasihat kepada direksi.

$\mathrm{H}_{2} \quad$ : Board size mempunyai pengaruh yang signifikan terhadap audit report lag.

\subsection{Leverage dengan audit report lag}

Leverage yang terlampau tinggi menggambarkan kegagalan suatu perusahaan dan meningkatkan fokus seorang auditor bahwa laporan keuangan tersebut kurang reliable atau kurang 
dapat dipercaya sehingga mengindikasikan perusahaan tersebut dalam keadaan kesulitan keuangan. Perusahaan dengan keadaan kesulitan keuangan dapat mungkin terjadi dikarenakan manajemen yang buruk dan dalam melakukan audit atas utang dibutuhkan waktu yang lebih lama karena lebih melibatkan banyak staf dan lebih rumit sehingga berpengaruh terhadap audit report lag.

$\mathrm{H}_{3} \quad$ : Leverage mempunyai pengaruh yang signifikan terhadap audit report lag.

\subsection{Ukuran perusahaan dengan audit report lag}

Ukuran perusahaan dapat diartikan sebagai besar atau kecilnya suatu perusahaan yang dinilai dari total aset yang dapat dimiliki oleh perusahaan. Perusahaan yang sangat sudah besar akan mempunyai internal control yang lebih baik. Hal tersebut dimungkinkan akan memperkecil kesalahan pada saat menyusun laporan keuangan, sehingga auditor yang melakukan proses audit dapat melaksanakan audit dengan lebih cepat.

$\mathrm{H}_{4} \quad$ : Ukuran perusahaan mempunyai pengaruh yang signifikan terhadap audit report lag.

\subsection{Ownership concentration dengan audit report lag}

Ownership concentration yaitu persentase jumlah dalam kepemilikan saham mayoritas di suatu perusahaan selain kepemilikan atas publik di dalam suatu struktur kepemilikan saham perusahaan. Semakin besar ownership concentration di dalam suatu perusahaan maka akan dapat mengurangi kebijakan manajemen perusahaan yang bersifat menyimpang. Hal ini dikarenakan mereka memiliki rasa kepemilikan yang besar juga.

$\mathrm{H}_{5} \quad$ : Ownership concentration mempunyai pengaruh yang signifikan terhadap audit report lag.

\section{METODE PENELITIAN}

\subsection{Populasi}

Populasi adalah kumpulan suatu pengukuran atau data pengamatan yang dilakukan terhadap orang, benda ataupun tempat. Populasi penelitian ini adalah seluruh perusahaan manufaktur yang terdaftar di Bursa Efek Indonesia periode 2013, 2014, 2015 dan 2016 sebanyak 151 perusahaan.

\subsection{Sampel}

Sampel merupakan sebagian dari populasi atau dalam istilah matematika dapat disebut sebagai himpunan bagian dari populasi. Sampel dalam penelitian ini diambil menggunakan metode purposive sampling yaitu teknik penentuan sampel yang tidak acak berdasarkan pertimbangan tertentu. Data perusahaan manufaktur berupa laporan keuangan yang diperoleh dari situs resmi Bursa Efek Indonesia yaitu www.idx.co.id. Adapun pertimbangan kriteria yang ditetapkan antara lain: (1) Perusahaan yang telah listing selama 4 tahun berturut-turut yakni tahun 2013, 2014, 2015 dan 2016; (2) Perusahaan yang telah menerbitkan laporan keuangan yang dinyatakan dalam mata uang rupiah; (3) Perusahaan yang telah memiliki kelengkapan data mengenai objek penelitian selama tahun 2013, 2014, 2015 dan 2016.

\subsection{Operasionalisasi variabel}


Variabel terikat yang diuji dalam penelitian ini yaitu audit report lag. Variabel bebas yang diuji dalam penelitian ini yaitu profitabilitas, board size, leverage, ukuran perusahaan, dan ownership concentration.

\subsection{Metode pengumpulan data}

Teknik pengumpulan data di dalam penelitian ini yaitu metode dokumentasi dengan menggunakan data-data sekunder, yang dapat diperoleh dari buku-buku di perpustakaan, jurnal ilmiah dan serta informasi lainnya yang relevan dalam topik penelitian. Data mengenai profitabilitas, board size, leverage, ukuran perusahaan, dan ownership concentration diperoleh dari situs resmi Bursa Efek Indonesia yaitu www.idx.co.id.

\subsection{Teknik pengolahan data}

Data yang sudah diperoleh akan diolah dan dianalisis menggunakan bantuan program komputer yaitu IBM SPSS Statistics 24. Pengujian yang dilakukan dalam melakukan penelitian ini yaitu dengan menggunakan analisis statistik deskriptif, uji asumsi klasik dan uji hipotesis.

\section{HASIL DAN PEMBAHASAN}

3.1. Deskripsi subyek penelitian

Dalam penelitian ini, akan dilakukan suatu pengukuran dengan menggunakan nilai minimum, maksimum, mean, standar deviasi serta jumlah sampel dari setiap variabel penelitian baik variabel independen maupun variabel dependen.

\subsection{Analisis statistik deskriptif}

Agar dapat dilakukan suatu perbandingan, maka analisis statistik deskriptif dapat dilakukan untuk empat periode secara keseluruhan. Hasil pengolahan data statistik deskriptif dapat dilihat pada tabel 2 dibawah ini.

Tabel 2. Hasil Analisis Statistik Deskriptif Descriptive Statistics

\begin{tabular}{|l|r|r|r|r|r|}
\hline & N & Minimum & Maximum & Mean & Std. Deviation \\
\hline ROA & 272 & $-54,84665$ & 74,84000 & 5,9219665 & 12,52334681 \\
BS & 272 & 4 & 27 & 9,45 & 4,483 \\
DAR & 272 &, 04000 & 3,03000 &, 5216834 &, 43657890 \\
SIZE & 272 & 25,24550 & 33,19881 & 28,1567515 & 1,69200522 \\
OC & 272 & 1 & 7 & 2,74 & 1,594 \\
ARL & 272 & 49 & 105 & 79,24 & 8,704 \\
Valid N (listwise) & 272 & & & & \\
\hline
\end{tabular}

Sumber: hasil pengolahan data menggunakan IBM SPSS Statistics 24 


\subsection{Hasil uji asumsi}

Uji asumsi klasik yang digunakan dalam penelitian ini terdiri dari uji normalitas, uji multikolinearitas, uji heteroskedastisitas, dan yang terakhir adalah uji autokorelasi.

Tabel 3. Hasil Uji Normalitas K-S Regresi Liniar Berganda One-Sample Kolmogorov-Smirnov Test

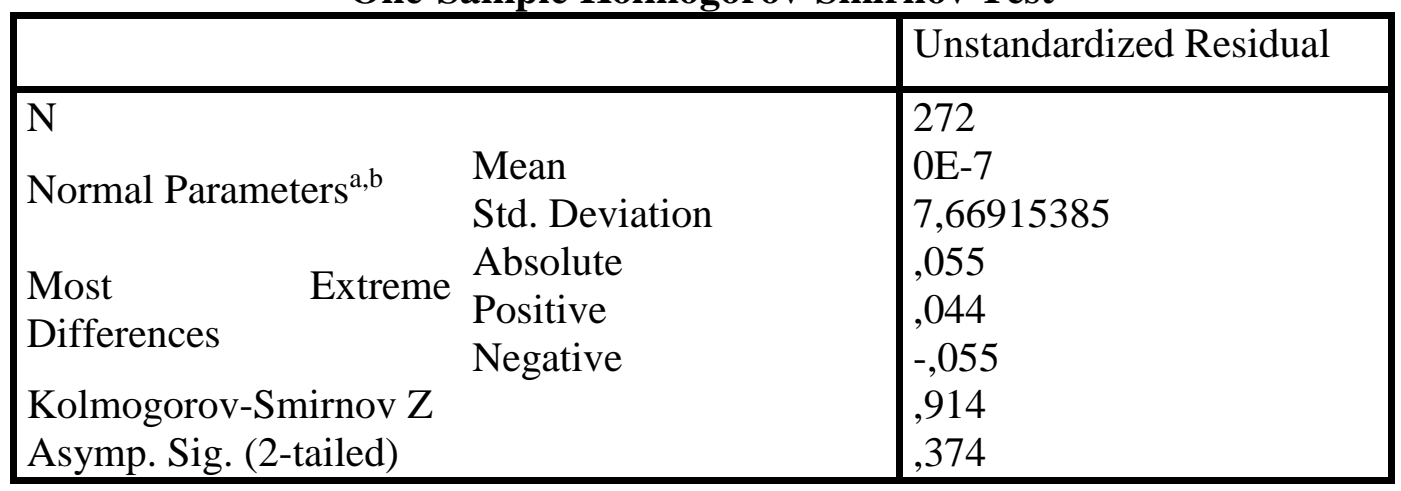

Tabel 4. Hasil Perhitungan Multikolinearitas Coefficients $^{\mathrm{a}}$

\begin{tabular}{|l|l|l|}
\hline \multirow{2}{*}{ Model } & \multicolumn{2}{|l|}{ Collinearity Statistics } \\
\cline { 2 - 3 } & Tolerance & VIF \\
\hline (Constant) & & \\
ROA &, 878 & 1,139 \\
BS &, 445 & 2,246 \\
DAR &, 952 & 1,051 \\
SIZE &, 460 & 2,174 \\
OC &, 862 & 1,160 \\
\hline
\end{tabular}

Tabel 5. Hasil Uji Autokorelasi Menggunakan Durbin-Watson Model Summary

\begin{tabular}{|l|l|l|l|l|l|}
\hline $\begin{array}{l}\text { Mode } \\
1\end{array}$ & $\mathrm{R}$ & $\mathrm{R}$ Square & Adjusted R Square & $\begin{array}{l}\text { Std. Error of the } \\
\text { Estimate }\end{array}$ & $\begin{array}{l}\text { Durbin- } \\
\text { Watson }\end{array}$ \\
\hline 1 &, $473^{\mathrm{a}}$ &, 224 &, 209 & 7,741 & 1,968 \\
\hline
\end{tabular}

Dari keempat pengujian asumsi yang sudah dilakukan, dapat disimpulkan bahwa semua data yang telah digunakan dalam penelitian ini sudah memenuhi persyaratan normalitas serta terbebas dari multikolinearitas, heterokedastisitas dan autokorelasi. Maka dari itu, model regresi sudah dapat digunakan dalam menguji pengaruh profitabilitas, board size, leverage, ukuran perusahaan dan ownership concentration terhadap audit report lag karena model regresi tidak bias, dapat diandalkan sebagai dasar dalam analisis dan telah memenuhi pengujian asumsi klasik. 


\subsection{Hasil uji hipotesis}

Teknik dalam melakukan pengujian hipotesis yang digunakan dalam penelitian ini adalah analisis regresi linear berganda, uji koefisien determinasi (R2), uji simultan (Uji F) dan uji parsial (Uji t).

Tabel 6. Hasil Output SPSS Variables Entered/ Removed Variables Entered/Removed ${ }^{\text {a }}$

\begin{tabular}{|l|l|l|l|}
\hline Model & Variables Entered & Variables Removed & Method \\
\hline 1 & OC, DAR, ROA, SIZE, BS & & Enter \\
\hline
\end{tabular}

Tabel 7. Hasil Pengujian Regresi Berganda

\section{Coefficients $^{\mathrm{a}}$}

\begin{tabular}{|c|c|c|c|c|c|c|c|}
\hline \multirow[t]{2}{*}{ Model } & \multicolumn{2}{|c|}{$\begin{array}{l}\text { Unstandardized } \\
\text { Coefficients }\end{array}$} & \multirow{2}{*}{$\begin{array}{l}\text { Standardized } \\
\text { Coefficients } \\
\text { Beta }\end{array}$} & \multirow[t]{2}{*}{$\mathrm{t}$} & \multirow[t]{2}{*}{ Sig. } & \multicolumn{2}{|c|}{$\begin{array}{l}\text { Collinearity } \\
\text { Statistics }\end{array}$} \\
\hline & B & \begin{tabular}{|l|} 
Std. \\
Error
\end{tabular} & & & & $\begin{array}{l}\text { Toler } \\
\text { ance }\end{array}$ & VIF \\
\hline (Constant) & 72,979 & 10,782 & & 6,769 &, 000 & & \\
\hline ROA &,- 015 & ,040 &,- 022 &,-- 373 &, 710 &, 878 & 1,139 \\
\hline BS &,- 820 &, 157 &,- 422 & $\mid-5,219$ &, 000 & ,445 & 2,246 \\
\hline DAR & 3,925 & 1,104 & , 197 & 3,555 &, 000 & ,952 & 1,051 \\
\hline SIZE & ,397 & ,410 & ,077 & ,970 &, 333 & ,460 & 2,174 \\
\hline OC & ,318 &, 318 & ,058 & 1,002 & ,317 &, 862 & 1,160 \\
\hline
\end{tabular}

Tabel 8. Hasil Pengujian Koefisien Determinasi $\left(\mathbf{R}^{2}\right)$ Model Summaryb

\begin{tabular}{|l|l|l|l|l|}
\hline Model & R & R Square & $\begin{array}{l}\text { Adjusted } \\
\text { Square }\end{array}$ & $\begin{array}{l}\text { Std. Error of the } \\
\text { Estimate }\end{array}$ \\
\hline 1 & $4^{\mathrm{a}}$ &, 224 &, 209 & 7,741 \\
\hline
\end{tabular}

Tabel 9. Hasil Pengujian Simultan (Uji F) ANOVA $^{\mathrm{a}}$

\begin{tabular}{|c|c|c|c|c|c|c|}
\hline & Sum of Squares & df & Mean Square & $\mathrm{F}$ & Sig. \\
\hline \multirow[t]{3}{*}{ - } & Regression & 4592,871 & 5 & 918,574 & 15,330 &, $000^{\mathrm{b}}$ \\
\hline & Residual & 15939,115 & 266 & 59,921 & & \\
\hline & Total & 20531,985 & 271 & & & \\
\hline
\end{tabular}


Tabel 10. Hasil Pengujian Signifikansi t (t-test) Coefficients $^{\mathrm{a}}$

\begin{tabular}{|l|l|l|l|l|l|}
\hline \multirow{2}{*}{ Model } & \multicolumn{2}{|l|}{$\begin{array}{l}\text { Unstandardized } \\
\text { Coefficients }\end{array}$} & Standardized Coefficients & \multirow{2}{*}{ Sig. } \\
\cline { 2 - 4 } & B & Std. Error & Beta & & \\
\hline (Constant) & 72,979 & 10,782 & & 6,769 &, 000 \\
ROA &,- 015 &, 040 &,- 022 &,- 373 &, 710 \\
BS &,- 820 &, 157 &,- 422 & $-5,219$ &, 000 \\
DAR & 3,925 & 1,104 &, 197 & 3,555 &, 000 \\
SIZE &, 397 &, 410 &, 077 &, 970 &, 333 \\
OC &, 318 &, 318 &, 058 & 1,002 &, 317 \\
\hline
\end{tabular}

3.5. Pembahasan hasil penelitian

a. Pengaruh profitabilitas terhadap audit report lag

Berdasarkan hasil pengolahan data yang telah dilakukan pada tabel 10, dapat dilihat bahwa variabel profitabilitas memiliki nilai signifikansi (Sig.) sebesar 0,710. Nilai signifikansi tersebut tentu lebih besar dari 0,05 yang dapat diartikan bahwa Ho1 diterima dan Ha1 ditolak. Oleh karena itu, dapat disimpulkan bahwa profitabilitas tidak memiliki pengaruh yang signifikan terhadap audit report lag pada perusahaan manufaktur yang terdaftar di Bursa Efek Indonesia.

b. $\quad$ Pengaruh board size terhadap audit report lag

Berdasarkan hasil pengolahan data yang telah dilakukan pada tabel 10, dapat dilihat bahwa variabel board size memiliki nilai signifikansi (Sig.) sebesar 0,000. Nilai signifikansi tersebut tentu lebih kecil dari 0,05 yang dapat diartikan bahwa Ha2 diterima dan Ho2 ditolak. Maka dari itu, dapat disimpulkan bahwa board size memiliki pengaruh yang signifikan terhadap audit report lag pada perusahaan manufaktur yang terdaftar di BEI periode 2013-2016.

\section{c. Pengaruh leverage terhadap audit report lag}

Berdasarkan hasil pengolahan data yang dilakukan pada tabel 10, dapat dilihat bahwa variabel leverage memiliki nilai signifikansi (Sig.) sebesar 0,000. Nilai signifikansi tersebut tentu lebih kecil dari 0,05 yang dapat diartikan bahwa Ho3 ditolak dan $\mathrm{Ha} 3$ diterima. Oleh karena itu, dapat disimpulkan bahwa leverage memiliki pengaruh yang signifikan terhadap audit report lag pada perusahaan manufaktur yang terdaftar di BEI periode 2013-2016.

d. Pengaruh ukuran perusahaan terhadap audit report lag

Berdasarkan hasil pengolahan data yang telah dilakukan pada tabel 10, dapat dilihat bahwa variabel ukuran perusahaan memiliki nilai signifikansi (Sig.) sebesar 0,333. Nilai signifikansi tersebut tentu lebih besar dari 0,05 yang dapat diartikan bahwa Ho4 diterima dan Ha4 ditolak. Maka dari itu, dapat diambil kesimpulan bahwa ukuran perusahaan tidak memiliki pengaruh yang signifikan terhadap audit report lag pada perusahaan manufaktur yang terdaftar di BEI periode 2013-2016.

\section{e. $\quad$ Pengaruh ownership concentration terhadap audit report lag}


Berdasarkan hasil pengolahan data yang dilakukan pada table 10, dapat dilihat bahwa variabel ownerhsip concentration memiliki nilai signifikansi (Sig.) sebesar 0,317. Nilai signifikansi tersebut tentu lebih besar dari 0,05 yang dapat diartikan bahwa Ho5 diterima dan Ha5 ditolak. Oleh karena itu, dapat ditarik kesimpulan bahwa ownership concenration tidak memiliki pengaruh yang signifikan terhadap audit report lag pada perusahaan manufaktur yang terdaftar di BEI periode 2013-2016.

\section{KESIMPULAN DAN SARAN}

4.1. Kesimpulan

Berdasarkan hasil penelitian dan pembahasan yang sudah diuraikan, maka dapat ditarik kesimpulan sebagai berikut: (1) Profitabilitas yang diproksi dengan Return on Asset (ROA) berpengaruh negatif dan tidak signifikan; (2) Board size yang diproksi dengan total jumlah personel dalam dewan komisaris yang ditambah dengan jumlah dewan direksi dalam suatu perusahaan berpengaruh negatif dan signifikan; (3) Leverage yang diproksi dengan debt to total asset ratio (DAR) berpengaruh positif dan signifikan; (4) Ukuran perusahaan yang diproksi dengan total aset berpengaruh positif dan tidak signifikan; (5) Ownership concentration yang diproksi dengan jumlah pemegang saham mayoritas yang memegang 5 persen atau lebih saham dari suatu perusahaan berpengaruh positif dan tidak signifikan.

\subsection{Saran}

Berdasarkan hasil penelitian yang dilakukan, maka terdapat beberapa hal perlu menjadi perhatian, yaitu antara lain: Auditor disarankan untuk dapat merencanakan pekerjaan lapangan yang lebih cermat sesuai dengan lingkungan dan risiko bisnis agar proses audit dapat dijalankan secara efektif dan efisien, hasil dalam penelitian ini diharapkan dapat memberikan informasi sehingga dapat dijadikan acuan dan bahan pertimbangan dalam melakukan analisis laporan keuangan di dalam pengambilan keputusan ekonomi, diharapkan juga dapat menambah studi literatur, memberikan landasan kepada penelitian selanjutnya dimana bukti empiris dapat dijadikan tambahan wawasan di dalam melakukan penelitian selanjutnya, memberikan pemahaman atau gambaran tentang lamanya audit report lag pada perusahaan yang terdaftar di Bursa Efek Indonesia (BEI), serta dapat memberikan informasi tentang definisi dan pengaruh profitabilitas, board size, leverage, ukuran perusahaan, dan ownership concentration. Peneliti selanjutnya juga diharapkan dapat melakukan penelitian dengan menambah variabel penelitian dan juga memperluas periode pengamatan.

\section{REFERENSI}

Ahmed M.I., dan Che-Ahmad A. (2016). Effects of corporate governance charasteristics on audit report lags. International Journal of Economics and Financial Issues, 6(S7), 159-164.

Alkhatib A., dan Marji Q. (2012). Audit reports timeliness: Empirical evidence from Jordan. Procedia - Social and Behavioral Sciences, (62), 1342-1349.

Arifuddin, Hanafi K., dan Usman A. (2017). Company size, profitability, and auditor opinion influence to audit report lag on registered manufacturing company in Indonesia Stock Exchange. International Journal of Applied Business and Economic Research, 15(19), 353367. 
BAPEPAM. (1997). Keputusan Ketua Badan Pengawas Pasar Modal No. KEP 11/PM/1997, Peraturan Nomor IX.C.7 Tentang Pedoman Mengenai Bentuk dan Isi Pernyataan Pendaftaran Dalam Rangka Penawaran Umum Oleh Perusahaan Menengah dan Kecil.

Eghlaiow S., Wickremasinghe G., dan Sofocleous S. (2012). A review of the empirical determinants of audit delay. Corporate ownership and Control, 9(2), 511-514.

Hassan Y.M. (2016). Determinants of audit report lag: Evidence from Palestine. Journal of Accounting in Emerging Emerald Group Publishing Limited, 6(1), 13-32.

Tiono, Ivena, dan Jogic. (2013). Faktor-faktor yang mempengaruhi audit report lag di Bursa Efek Indonesia. Business Accounting Review, 2(1), 65-76.

\section{Sumber lain:}

$\underline{\text { www.idx.co.id }}$ 